\title{
BUCCAL FILM: A NOVEL APPROACH FOR ORAL MUCOSAL DRUG DELIVERY SYSTEM
}

\author{
SHIFA HAJU*, SHEELA YADAV, REESHA BAIG, GAURANG SAWANT
}

Department of Pharmaceutics, HK College of Pharmacy, Oshiwara, Mumbai, Maharashtra, India. Email: shifahaju123@gmail.com

\author{
Received: 10 September 2020, Revised and Accepted: 20 November 2020
}

\begin{abstract}
Buccal drug delivery especially refers to the delivery of drugs through the buccal mucosal membrane lining of the oral cavity. For geriatric and pediatric patients who undergo difficulties in swallowing conventional oral solid dosage forms, the buccal film is a better alternative. The buccal film is appropriate for the drugs which experience high first-pass metabolism and is used for enhancing bioavailability with reducing dosing frequency to mouth plasma peak levels, which thus limit side-effects and make it cost-effective. It enhances the efficacy of API in the oral cavity after the contact with less saliva as contrasted to tablets, without chewing and no need for water for administration. This review briefly describes the advantages and limitations of buccal film, an anatomical structure of oral mucosa, highlighting the mechanisms of drug permeation, formulation technologies, methodology in evaluating buccal film, and recent advances of the buccal film as a tool for drug delivery for various treatments.
\end{abstract}

Keywords: Buccal film, Oral mucosal drug delivery system, Bioavailability enhancement.

(C) 2021 The Authors. Published by Innovare Academic Sciences Pvt Ltd. This is an open access article under the CC BY license (http://creativecommons.org/ licenses/by/4.0/) DOI: http://dx.doi.org/10.22159/ajpcr.2021v14i1.39687. Journal homepage: https://innovareacademics.in/journals/index.php/ajpcr

\section{INTRODUCTION}

Among the various routes of drug delivery, oral-mucosal drug delivery offers distinct advantages as buccal mucosa is the most suited for local, as well as systemic delivery of drugs [1]. The buccal film is a drug delivery system that has rapidly gained acceptance as a new way of drug administration, improved safety and efficacy of drug molecule, and the enhanced onset of action [2]. The buccal film is an elegant and effective dosage form with enhanced bioavailability when compared to other dosage forms, as it by-passes the hepatic first-pass metabolism [3]. The site of drug administration in oral-mucosa is subdivided into buccal and sublingual mucosa [4]. The order of permeability of the oral cavity is given as sublingual $>$ buccal $>$ palatal [5]. The buccal mucosa being comparatively immobile mucosa than sublingual mucosa and readily available, it makes it more advantageous for retentive systems used for oral-mucosal drug delivery [6]. The buccal film may be preferred over a buccal tablet, in terms of comfort and flexibility [7]. The buccal film is well known that the absorption of therapeutic compounds from the oral-mucosa provides direct entry of a drug into systemic circulation through the jugular vein [8]. The advantages of buccal film are low cost,ease of administration, high patience compliance [9]. Active pharmaceutical ingredients (API), various polymer, plasticizer, saliva stimulating agent, permeation enhancers, sweeteners, flavoring agents, preservatives, and color, are used in formulating buccal film. The buccal film is essentially positioned on oral mucosal tissues, which is quickly wet by saliva in the mouth; the film is quickly hydrated and follows on to the site of application [10]. The main property of buccal film is that, because of the large surface area of the film, it allows quick wetting of the film which increase the absorption of the drug quickly as compared to the tablets. The buccal mucosa is rich with blood supply, which acts as a perfect and fast site for the absorption of drug [11].

\section{ADVANTAGES OF BUCCAL FILM}

The advantages of buccal films are as follows:

1. The buccal film shows a comparatively rapid onset of action with lesser side effects than other routes of administration [12].

2. Flexible and portable so provide ease in transportation during handling and storage [13].

3. Accurate dose administration [13].

4. Enhanced stability and safety [14].

5. As compared to the intravenous delivery system, mucosal delivery systems have the easy application of dosage forms with no pain on administration leading to improved patient compliance [15].

6. Avoids the first-pass metabolism and hence the drug will not get exposed to the gastrointestinal fluid [16].

7. By incorporating mucoadhesive polymers of "SR" grade, this system can also attain sustained drug delivery [17].

8. Low dose frequency due to longer duration of residence time along with controlled drug release [18].

9. Due to direct contact and adhesion buccal film remains for a long period at the application site and thus increases bioavailability using a low concentration of API [19].

10. Environmental factors such as acidic and degradation environment found in the oral drug delivery can be evaded by buccal film dosage form [20].

11. Appropriate dosage form for geriatric and pediatric patients experiencing difficulty in swallowing or nauseating and patients who are mentally ill or physically disabled [21].

\section{DISADVANTAGES OF BUCCAL FILMS}

There are numerous advantages of the buccal film but with few disadvantages lead to a main challenging formulation.

1. Barrier properties of the oral mucosa [22].

2. Restriction of drinking and eating [23].

3. Drugs with a lower dose requirement can be administered [23].

4. Dilution of drug and swallowing of the formulation due to vigorous secretion of saliva [24].

\section{ANATOMY AND PHYSIOLOGY OF ORAL MUCOSA}

The oral mucosa acts as an important route for the delivery of drugs. The oral cavity has been diagrammatically represented, as shown in Fig. 1. The oral cavity presents the total surface area of about $100 \mathrm{~cm}^{2}$, that is, lined by mucus membranes [25]. The oral cavity consists of about one-third of the buccal surface of $0.5 \mathrm{~mm}$ thickness epithelium [26]. Following are several sites that have been used for drug administration in oral cavity, namely, are:

1. Buccal cavity

2. Sublingual cavity

3. Lingual area

4. The palate

5. Gingival region 
The oral mucosal cavity comprises the multilayered epithelial tissues that are additionally covered by mucus. Here is a basal membrane present inward to the epithelial tissues. Inside the basal membrane, there is a layer of connective tissue called lamina propria. The lamina propria provides a mechanical support function. After this, the submucosal part begins. It contains the different blood vessels as well as nerves from the central nervous system. The cross-section of the buccal mucosa is represented in Fig. 2. The sub-mucosal part provides the highest vascularity for the complete absorption of the drugs. The human oral mucosa contains both keratinized epithelium (found in the gingival and part of the hard palate) and the non-keratinized epithelium (found on the surface of the distensible lining mucosa, of the soft palate, floor of the mouth, lips, and cheek) [25].

The buccal region is the part of the mouth, limited anteriorly, and laterally by the lips and cheeks, posteriorly and medially by the teeth as well as gums, or above and below by the impressions of mucosa from the lips and cheeks to the gums. Buccal mucosa's essential role is similar to the skin, which is protection of underlying structures from foreign agents [27]. The permeability of the buccal mucosa is $4-4000$ times greater than that of the skin approximately. The order of permeability of the oral mucosa is sublingual $>$ buccal $>$ palatal which relies on relative thickness and level of keratinization [26].
The mucus layer

To the mucosal epithelial surface a clear and viscid secretion which is thin, continuous gel covers are adherent called mucus. In the human, the mean thickness of this layer varies from around 50 to $450 \mu \mathrm{m}$. The goblet cells lining the epithelial or by extra-ordinary exocrine glands that secreted mucus. The specific composition of the mucus layer differs significantly relying on the species, the anatomical location, and the pathophysiological state [28]

However, it has the following general composition:

\begin{tabular}{ll}
\hline Components & Percentage \\
\hline Water & 95 \\
Glycoproteins and lipids & $0.5-5$ \\
Mineral salts & 1 \\
Free proteins & $0.5-1$ \\
\hline
\end{tabular}

\section{MECHANISM OF BUCCAL FILM}

Buccal film when, simply positioned on the patient's oral-buccal mucosal tissue, instantly become wets by saliva. Due to the presence of hydrophilic polymers and other excipients, the film quickly hydrates, dissolves, and releases the medication, thus ensuring the absorption of medicament [29].

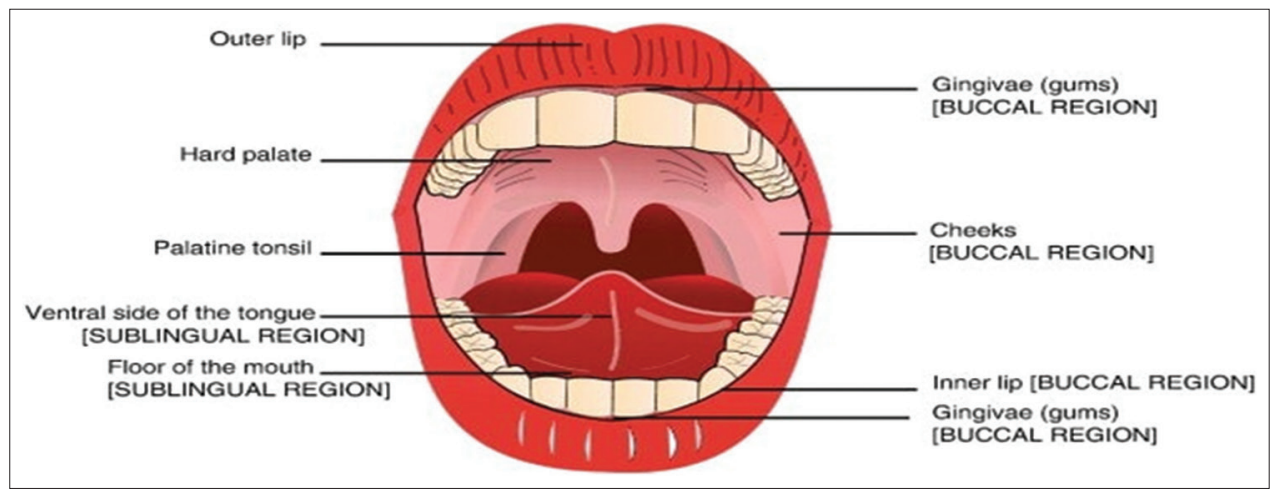

Fig. 1: Anatomy of oral cavity. Adapted from Kraan et al. 2014, Buccal and Sublingual Vaccine Delivery. Journal of Controlled Release.190:580-92. Copyright permission obtained under CC-BY-NC-ND License. (https://creativecommons.org/licenses/by-nc-nd/3.0/)

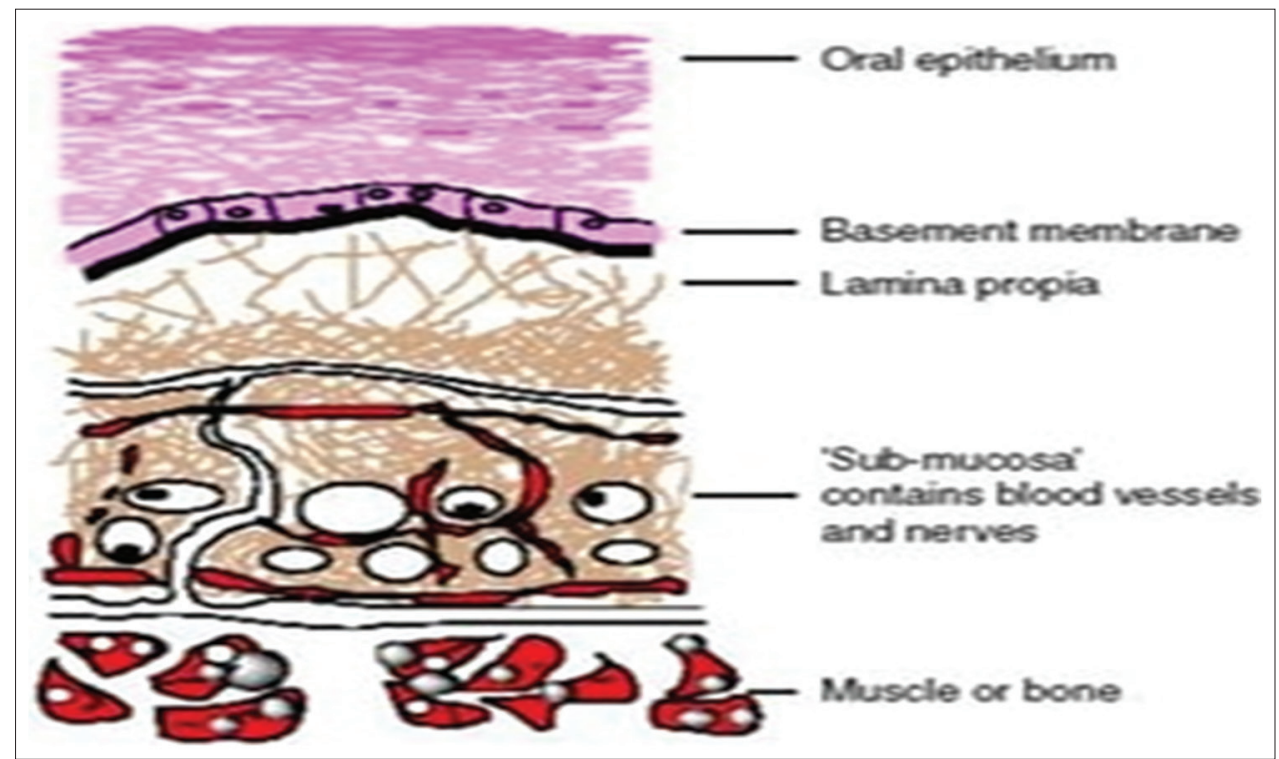

Fig. 2: Cross-sectional view of buccal mucosa. Adapted from Gureja et al. Bucco adhesive drug delivery system. Available at (https://www. pharmatutor.org/articles/bucco-adhesive-drug-delivery-system). Copyright permission obtained from website of pharmatutor (https:// www.pharmatutor.org) 
Drug absorption pathways

The drug transport mechanism through buccal mucosa involves two major pathways:

1. Trans-cellular (intracellular)

2. Para-cellular (intercellular)

The absorption capability of the buccal mucosa is affected by the lipid solubility and molecular weight of the diffusant. Absorption of a certain drug through buccal mucosa is found to increase when carrier $\mathrm{pH}$ is lowered and decreased by an increase in $\mathrm{pH}$ [30].

\section{Buccal film dosage form release mechanism}

Buccal film dosage form further divided into three types they are as follows:

1. Type I: Single layer device suffers from drug loss due to multidirectional drug release on significant swallowing.

2. Type II: Impermeable backing layer is superimposed on the top of the drug-loaded bio-adhesive layer prevents loss from the top surface in the oral cavity.

3. Type III: Unidirectional drug release can be achieved by coating every face of the dosage form except the one that is in contact with buccal mucosa. Since the drug release from one side will minimize drug loss [27].

\section{Theories of bio-adhesion}

Several theories have been proposed to explain the fundamental mechanism of attachment.

1. Electronic theory

2. Adsorption theory

3. Diffusion theory

4. Wetting theory

5. Absorption theory

6. Fracture theory

Among the above mention theories, adsorption theory plays an important role in the adhesion of the buccal film mechanism.

\section{Adsorption theory}

As per absorption theory, after initial contact between the buccal mucosal surface and the material adheres to it has their own surface energy.

Chemical bonds involves following forces:

1. Primary chemical bond: Such as covalent nature, this is undesirable because higher strength may result in a permanent bond.

2. Secondary chemical bond: Different forces of attraction includes electrostatic forces, Van der Waals forces, hydrogen, and hydrophobic bonding, which are weak in nature, thus produces a semi-permanent bond [28].

\section{IDEAL CHARACTERISTICS OF BUCCAL FILM}

1. All degradation products and polymers should not be toxic, poisonous, and irritant and must be free from impurities [31].

2. It should have good spread ability, swelling, wetting, solubility, biodegradability, viscoelastic properties, and biocompatible $\mathrm{pH}$ range [32].
3. It should have an appropriate shelf life without decomposition on storage [33].

4. It should adhere quickly to the buccal mucosa and should have good mechanical strength [34].

5. It should have adequate patient compliance without obstructing normal functioning such as talking, eating, and drinking [34].

6. Drugs should release in a controlled manner [34].

7. Unidirectional passage of drug release should be provided toward the mucosa [35].

8. The rate and extent of drug absorption should be facilitated [35].

9. The dose should be lower than $20 \mathrm{mg}$ with low molecular weight [36].

10. It should have good stability in water and saliva [36].

11. It should have the ability to permeate oral mucosal tissue [36].

12. It should not have a bitter or unpleasant taste [37]

\section{COMPOSITION OF BUCCAL FILM}

\section{Active ingredients}

The buccal film technology has the potential for delivery of variety of APIs [38]. Active pharmaceutical substances can be from any Biopharmaceutical Classification System (BCS) class of pharmaceutically active substances that can be given either orally or even by buccal mucosa. To make a successful and effective formulation the drug to be administered should be $<20 \mathrm{mg}$ daily [39]. Table 1 gives a list of marketed buccal films.

\section{Plasticizer}

Plasticizers are very critical for the formulation of a buccal drug delivery system [42]. They help by improving the mechanical properties of the buccal film which includes tensile strength, elongation of the films while additionally provide other advantages such as a reduction in the brittleness of the film and enhanced flexibility along with an increment in the flow property of the polymer and slashing of the glass transition temperature of the polymer. The amount of the polymer used can be remodeled which subsequently alters the properties of the final film so obtained. Examples of plasticizers include glycerin, sorbitol, propylene glycol, polyethylene glycol, tri-acetin, dibutyl phthalate, tri-ethylcitrate, acetyl tri-ethyl-citrate, and other citrate esters. The amount of the plasticizer to be used can vary from about 0 to $20 \% \mathrm{w} / \mathrm{w}$ of the dry polymer weight. Plasticizers also upgrade the folding capacity of the final buccal films [43]. Glycerin was employed as a plasticizer in preparation of fast dissolving buccal films containing a solid dispersion of isradipine [44].

\section{Sweetening agents}

Sweeteners play a pivotal role in the pharmaceutical preparations which have an aim of either disintegration or dissolution in the mouth. The traditional sources of sweeteners are, namely, sucrose, dextrose, fructose, glucose, liquid glucose, and iso-maltose. Fructose is a versatile sweetener employed in industries as sweetness of fructose is recognized quickly in the mouth when compared against sucrose and dextrose and while it is more sweeter than sorbitol and mannitol as well as polyhydric alcohols such as sorbitol and mannitol. Polyhydric alcohols offer reduced carcinogenic chances and lack the bitter after taste which is an important parameter in preparation of oral preparations [45]. Herbal sweeteners can also be used for example being Rebiana, derived from the plant Stevia rebaudiana (South American plant) having more than 200-300 times

Table 1: List of marketed buccal films

\begin{tabular}{llll}
\hline Active drugs & Uses & Manufacturer & Reference \\
\hline Fentanyl Citrate & Opioid analgesic & Meda Pharmaceuticals, Inc & Satheesh Madhav et al. 2012 [39]. \\
Buprenorphine & Opioid analgesic & Bio delivery Sciences International & Satheesh Madhav et al. 2012 [39]. \\
Loratadine & Anti-histaminic & Hughes medical corp. & Dahiya et al. 2009 [40]. \\
Donepezil & Alzheimer's & Labtec & Dahiya et al. 2009 [40]. \\
Simethicone & Bloating, belching & Novartis & Dahiya et al. 2009 [40]. \\
Phenylephrine & Nasal decongestant & Pfizer & Dahiya et al. 2009 [40]. \\
Menthol Canker sore & Cooling sensation in throat pain & Innozen & Dahiya et al. 2009 [40]. Canker sore \\
Choline & Salicylate & To treat aphthous lesions & Daněk et al. 2017 [41]. \\
\hline
\end{tabular}


sweetness of sucrose [46]. Artificial sweetener such as Saccharin Sodium was also employed in formulation of buccal film [47].

\section{Surfactants}

Surfactants are utilized as solubilizing or wetting or dispersing agents with the aim that the film gets melted within seconds and liberate the active agent instantly. Surfactants also enhance the solubility of poorly soluble drugs in fast-dissolving buccal films. Examples include polaxamer407, sodium lauryl sulfate, benzalkonium chloride, tweens, and spans [48]

\section{Flavoring agent}

Flavoring agents are used to providing flavor to the product which is also a factor of patient compliance. Flavoring agents can be chosen from a wide variety of materials including synthetic flavor oils, oleoresins, and extract obtained from multiple parts of the plants such as leaves, fruits, and flowers. Flavors can be employed solo or in conjunction with each other. Peppermint oil, cinnamon oil, spearmint oil, and oil of nutmeg are examples of flavor oils, whereas vanilla, cocoa, coffee, chocolate, and citrus are fruity flavors derived from fruits. Flavors can be used alone or in one or more combination. The quantity of flavor required to hide the taste of the original drug depends on the flavor category and its power. Mostly, a maximum of $10 \% \mathrm{w} / \mathrm{w}$ flavors is added in the buccal film formulations. To enhance the flavor strength as well as to increase the pleasant sensation of the product, cooling agents such as mono-methyl succinate can be added [49,50].

\section{Coloring agent}

The patient compliance of oral disintegrating films relies on the flavoring agent incorporated into it which, in turn, is dependent on the category of drug present in the formulation, for example, Peppermint oil and cinnamon oil [51].

\section{Saliva stimulating agent}

The main aim of saliva stimulating agent is to increase the production of saliva and help dissolve the buccal film faster. The concentrations in which they are used ranges from $2 \%$ to $6 \%$ [52]

\section{Backing membrane}

The backing membrane is an impermeable covering that has been attached to one side of the buccal film so that the drug is allowed to release into the oral cavity only in one direction and it also prevents leakage of the drug from the other side. 1\% Ethyl cellulose was used as a backing membrane in preparation of an opioid drug [53]

\section{Polymers}

Many polymers are within easy reach for the production of fast dissolving buccal films. The polymers can be used exclusively or in conjunction to give the required film properties. The film procured should be strong enough to withstand any damage while handling or during transportation. The robustness of the strip hangs on the type of polymer and the concentration used in the formulation. The many polymers employed in production fast-dissolving films include cellulose or cellulose derivatives, pullulan, gelatin, hydroxyl propyl methyl cellulose (HPMC), hydroxyl ethyl cellulose (HEC), hydroxyl propyl cellulose (HPC), polyvinyl pyrrolidone (PVP), carboxymethyl cellulose (CMC), polyvinyl alcohol (PVA), sodium alginate, xanthine gum, tragacanth gum, guar gum, acacia gum, methyl methacrylate (MMA) copolymer, and hypromellose are most regularly employed for the production of fast-dissolving films. Pullulan is a natural polymer derived from non-animal origin and has no need for chemical modification up to $50-80 \% \mathrm{w} / \mathrm{w}$ of pullulan can be substituted by starch in the preparation of fast dissolving films without wasting the desired properties of pullulan. Combining microcrystalline cellulose (MCC) and malt dextrin can also be employed to make fast dissolving films. Investigation of many polymers for application in the production of oral fast-dissolving strips was done. Different polymers such as HPMC E15, HPMC K4M, HPMC E5, PVP, PVA, gelatin, Eudragit RL100, and pullulan were used to make fast-dissolving buccal films; by employing solvent casting method. Conclusions proved that pullulan reigns supreme for oral fast-dissolving strips [54]. Klucel HXF Pharm (Hydroxypropyl cellulose) was employed as a mucoadhesive polymer in formulating a buccal film comprising a polyphenol [55].

\section{METHODS OF PREPARATION OF BUCCAL FILMS}

The following methods are used in the preparation of buccal films:

\section{Semisolid casting}

The semisolid casting method comprises the below-given steps:

1. A water-soluble film-forming polymer solution is prepared.

2. The resulting solution so formed is poured into a solution of acidinsoluble polymer (e.g., cellulose acetate phthalate, and cellulose acetate butyrate).

3. The required amount of plasticizer is incorporated to obtain a gels mass.

4. In the last step, the gel mass is transformed into the films or ribbons by application of heat controlled drums. The diameter of the film should be approximately $0.015-0.05 \mathrm{in}$. The proportion of the acidinsoluble polymer to film-forming polymer should be 1:4 [56].

\section{Solid dispersion extrusion}

The expression of solid dispersions relates to the dispersion of one or more active ingredients in a chemically inactive carrier in a solid-state in the attendance of amorphous hydrophilic polymers.

1. The drug is dissolved in a suitable liquid solvent.

2. Then, the solution is then added into liquid polyethylene glycol, which is achieved when heated above $70^{\circ} \mathrm{C}$.

3. Ultimately the solid dispersions are molded into the films by the employment of dies.

Some safeguard measures must be taken care of while using this method such as the chosen solvent or dissolved drug may immiscible with liquid polyethylene glycol and polymorphic form of the drug precipitated in the solid dispersion may get altered by the liquid solvent used [57].

\section{Solvent casting method}

The solvent casting method is most commonly used for the production of buccal films. This procedure involves the below-given steps:

1. Water-soluble components (polymers) are dissolved in water to form a single viscous solution.

2. API and other excipients are dissolved in an appropriate solvent to form a lucid viscous solution.

3. Both the solutions are blended and the final solution is reformed into a film and permitted to dehydrate, as shown in Fig. 3. [58-63].

\section{Rolling}

In this technique, the film is produced by making a pre-mix, followed by the incorporation of an active ingredient and subsequently the formation of a film.

1. Produce a pre-mix comprising a film-forming polymer, polar solvent, and other additives with exception of a drug.

2. Incorporate pre mix to master batch feed tank

3. Transfer it by a $1^{\text {st }}$ metering pump and control valve to one or all of the mixers.

4. Add the desired quantity of the drug to the desired mixer.

5. Mix the drug with master batch pre-mix to give a homogenous matrix.

6. Then, a fixed quantity of uniform matrix is then added to the pan utilizing the $2^{\text {nd }}$ metering pump.

7. The film is ultimately produced on the base material and transported away utilizing a support roller.

8. The wet film is then dehydrated by supervised bottom drying [65]

\section{BUCCAL FILMS USED IN FORMULATION OF SOLUBLE AND} INSOLUBLE DRUGS

Bioadhesive buccal film of ketoprofen was produced using an amalgamation of various polymers. The conclusions revealed that 


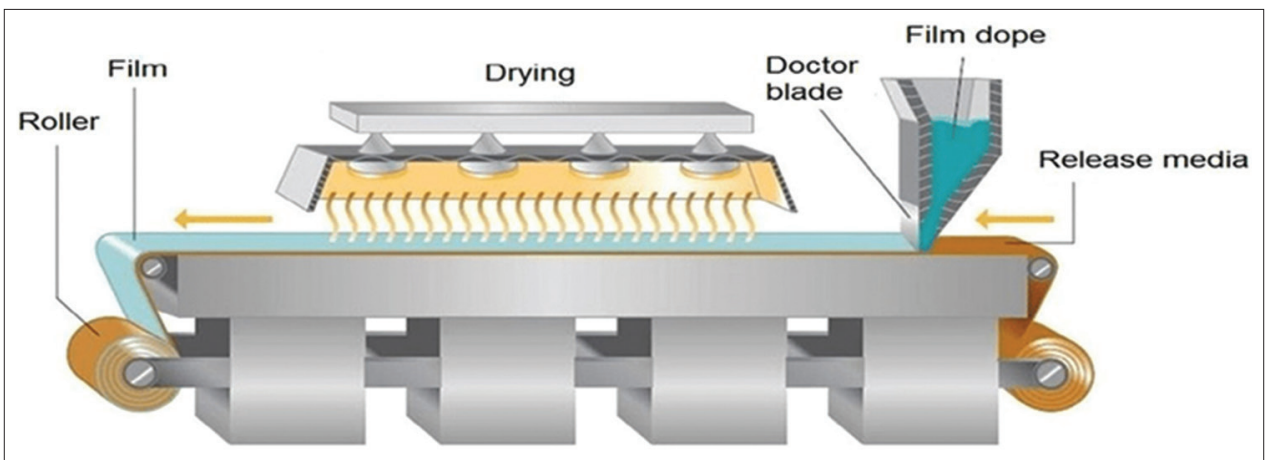

Fig. 3: Solvent casting method for manufacturing of buccal film. Adapted from Reference [64]. Copyright permission obtained under creative commons (CCBY) license (http://creativecommons.org/licenses/by/4.0/)

in vivo in vitro (IVIVC) was about 0.975 thus demonstrating a good link between in vivo and in vitro tests. The ex vivo release studies expressed ketoprofen attaining the therapeutic concentration in the plasma after about $1 \mathrm{~h}$. In regards to mucoadhesion ability, the batch was manufactured using polycarbophil as the polymer exhibited the highest mucoadhesion power of about $61 / 2$ [66]. A buccal film for delivery of anti-diabetic drug glimepiride was formulated using a novel nanocarrier armed with D-a-tocopherol polyethylene glycol 1000 succinate micelles (TPGS) also known as Vitamin E in common terms. The film was compared with a reference film of glimepiride (GMD) with the absence of the nanocarrier which was subsequently labeled with a fluorescent compound. The results revealed that the mathematical design so used did not fail to boost the factors that increase the liberation of GMD in a single direction from the transmucosal film packed with TPGS micelles in a controlled and foreseen manner. The boosted formulation demonstrated that the diffusion of GMD from the film was preferable towards TPGS micelles. The boosted one direction release of GMD transmucosal film was about $93.9 \%$ in $6 \mathrm{~h}$ compared to $60.41 \%$ of GMD release from the standard GMD film. This conclusion was established by its property to transport the GMD across the buccal mucosa, thereby showed by the ferocity of fluorescence with the fluorescence-labeled upgraded formulation [67]. Chlorzoxazone was modified by solid dispersion technique to refine its solubility and then incorporated it in buccal film. The findings revealed that the drug chlorzoxazone when formulated by a solid dispersion method showed greater dissolution and sustained release than the real mixture of the same drug and polymer HPMC K4 M [68]. A buccal film of Enalapril Maleate armed in a pullulan buccal film was formulated. The experiment of in vitro release profile of enalapril maleate fast-dissolving film and enalapril maleate tablets were performed in buffer solution $(\mathrm{pH} \mathrm{6.8)}$ and water. The findings revealed that after the elemental $5 \mathrm{~min}$ of the dissolution test, the polymeric film liberated $100.30 \%$ of the enalapril maleate into the buffer solution and $98.31 \%$ into water. Under matching conditions, the enalapril maleate from tablets showed a release of $5.1 \%$ into the buffer solution and $4.8 \%$ into water. These outcomes of this experiment give proof to both the experimental conditions of performing the in vitro dissolution test, as well as the proposal to employ these mucoadhesive buccal films for enalapril maleate administration [69]. Olmesartan Medoxomil (OMX) mucoadhesive buccal film was formulated where in the outcomes of the experiment revealed that therapeutic levels of OMX can be given through the buccal route as well as the films exhibited sustained release over more than $7 \mathrm{~h}$. The study concluded that these erodible mucoadhesive buccal films comprising Olmesartan can be very optimistic for fruitful doses to systemic circulation as well as avoiding the first-pass metabolism thus increasing its half-life [70]. Production and assessment of buccal films containing prototype drug of paracetamol as soluble and indomethacin as insoluble drug individually by employing carrageenan as the base and different grades of polyethylene glycol. The results revealed that the transformation of crystalline drugs to the amorphous form in the course of film formation as well as the film matrix exhibited the property to conserve the two prototype drugs in a stable amorphous form throughout the storage period of over 12 months. The films showed perfect release patterns within acceptable periods, after swelling and diffusion of the polymer matrix, under settings representing those of saliva [71].

\section{EVALUATION OF BUCCAL FILM}

\section{Weight variation}

A calibrated weighing balance was used for weighing buccal film. Each film is weighed individually and calculated. The average weight of all films is calculated and the actual weight of the film is analyzed [72].

\section{Thickness}

A calibrated micrometer screw gauge was used for evaluation of the thickness of the buccal film. Five different points on the film are measured (four on the corners and one in the center) and mean thickness is calibrated. This step is important to ensure the uniformity of thickness as well as accurate dosing in the film due to their correlation [73].

\section{Tensile strength}

The property of film that requires load causing deformation and finally failure of a film is called tensile strength. Two clamps spaced at equidistance are position in such a way that film strips are placed in between them. By applying load at rupture and knowing the crosssectional area of fractured film, a tensile film can be calculated by the following equation [74]:

Tensile strength $\left(\mathrm{N} / \mathrm{mm}^{2}\right)=$ Breaking force $(\mathrm{N}) /$ Cross-sectional area of sample $\left(\mathrm{mm}^{2}\right)$.

\section{Surface $\mathbf{p H}$}

For determination of surface $\mathrm{pH}, 2 \% \mathrm{w} / \mathrm{v}$ agar in isotonic phosphate buffer $\mathrm{pH} 6.8$ was dissolved and poured into the Petri dish for preparation of agar plate and was gelled at room temperature. Buccal films were placed on the surface of the agar plate for $2 \mathrm{~h}$ until they swell completely. $\mathrm{pH}$ indicator paper was used for measuring surface $\mathrm{pH}$ after 90 s change in color was observed comparing it with a standard color scale [75].

\section{Folding endurance}

For the measurement of folding endurance, three films were cut into appropriate size. By folding one film at the same place repeatedly or by folding up to 300 times till it breaks, folding endurance can be determined. The value of folding endurance can be identified when the film does not break even after folding the film multiple times [76].

\section{Drug content uniformity}

Drug uniformity was determined by dissolving 5 films weighed previously in $100 \mathrm{ml}$ of isotonic phosphate buffer $\mathrm{pH} 6.8$ with the help of a magnetic stirrer for $2 \mathrm{~h}$. Further, this solution was filtered with Whatman filter paper, and after suitable dilution, drug was analyzed using a spectrophotometer [77]. 
Percentage moisture loss test

Two films of $2 \times 2 \mathrm{~cm}^{2}$ were placed in the desiccator with anhydrous calcium chloride, percentage moisture loss was determined. The films were taken out after 3 days and were weighed. Using the formula below, percentage moisture loss was calculated [78].

Percentage Moisture Loss $=[$ (Initial weight - Final weight $) /$ Initial weight] $\times 100$

\section{Percentage moisture uptake}

Films were kept in the desiccator at room temperature for $24 \mathrm{~h}$ with saturated potassium chloride solution and maintained $84 \%$ relative humidity. The films were taken out and weighed after $24 \mathrm{~h}$. Percentage of moisture uptake can be calculated by the following formula [78].

Percentage moisture uptake $=[$ (Final weight - Initial weight $) /$ Initial weight $] \times 100$

\section{Swelling index}

Each buccal film was weighed individually (W1) and placed in the Petri dish separately containing phosphate buffer $\mathrm{pH}$ 6.8. Buccal films were removed using filter paper so that excess surface water is separated from the Petri dish and weighed again (W2). Swelling index (S1) was calculated using the formula: [79]

$\mathrm{SI}=(\mathrm{W} 2-\mathrm{W} 1) / \mathrm{W} 1$

Where;

SI = Swelling index

W2 $=$ Final weight

$\mathrm{W} 1$ = Initial weight

\section{In vitro disintegrating time}

It can be visually analyzed in a Petri dish with $2 \mathrm{ml}$ of distilled water by swirling after every $10 \mathrm{~s}$. The time taken by the film to disintegrate or break is noted and recorded as the in vitro disintegration time [80].

\section{In vitro dissolution study}

USP type II apparatus (Basket type apparatus) was used for dissolution studies with $\mathrm{pH} 6.8$ buffer $(50 \mathrm{ml})$ as a dissolution medium at $37^{\circ} \mathrm{C}$ temperature and speed at $50 \mathrm{rpm}$. $1 \mathrm{ml}$ of sample solution was withdrawn and equilibrated with a fresh dissolution medium. Whatman filter paper of $0.45 \mu \mathrm{m}$ was used to filter the buccal films and API was analyzed spectrophotometrically at $\lambda_{\max }[81]$.

\section{In vitro drug release}

Franz diffusion cell assembly was used for in vitro drug release studies. It consists of two compartments, one of the receptor chambers containing a buffer solution of $\mathrm{pH} 6.8$ and other donor compartment containing $10 \mathrm{mg}$ of the drug. A dialysis membrane (Mol. Wt 1200014000) which was previously soaked for $2 \mathrm{~h}$ in receptor medium was placed in between these compartments to separate it from each other. To avoid disruption in the ongoing process, it was ensured that no air bubbles were seen between the membrane and liquid surface. During the entire process, the temperature was maintained at $37^{\circ} \mathrm{C}$ by circulating water bath. At a specific time interval, till $8 \mathrm{~h} 0.5 \mathrm{ml}$ of the sample was withdrawn from the receptor chamber and filled with fresh buffer. Suitable dilution was carried out and the amount of drug release was spectroscopically analyzed. The flux value was identified by the following formula [82]:

Flux $=$ Amount of drug released $(\mathrm{mg}) /$ Time $(\mathrm{hr}) \times$ Area $\left(\mathrm{cm}^{2}\right)$

\section{Ex vivo mucoadhesion time}

For determining the mucoadhesion time, the buccal film is applied to the fresh buccal mucosa of sheep or rabbit which is tied on a glass slide. The buccal film is wetted with a drop of phosphate buffer $\mathrm{pH} 6.8$ and applied with a mild force on the buccal mucosa for $30 \mathrm{~s}$ using fingertips. In a beaker containing $200 \mathrm{ml}$ of phosphate buffer $\mathrm{pH} \mathrm{6.8,} \mathrm{the} \mathrm{glass}$ slide is kept at $37^{\circ} \mathrm{C} \pm 1^{\circ} \mathrm{C}$. To simulate the environment of the buccal cavity, a $50 \mathrm{rpm}$ stirring speed is applied after $2 \mathrm{~min}$ and film adhesion is regulated for $24 \mathrm{~h}$. The time taken for visible changes in shape and color is recorded along with the collapsing time of the film [45].

\section{Ex vivo permeation studies}

For performing permeation studies modified Franz diffusion cell was utilized. Two compartments, one of the donor compartments and other receptor compartments were seen of $25 \mathrm{ml}$ capacity. To maintain the temperature at $37^{\circ} \mathrm{C}$, the receptor compartment was enclosed with a water jacket consisting of $23 \mathrm{ml}$ of $\mathrm{pH} 6.6$ phosphate buffer. The separated buccal epithelium was mounted between the two chambers and the entire assembly was placed on a magnetic stirrer by putting a magnetic bead coated with Teflon. The buccal film was kept aside for stabilization after which $1 \mathrm{ml}$ of the sample was withdrawn at regular intervals and was suitably diluted for analyzing it spectrophotometrically [83].

\section{Stability studies}

Stability studies are undertaken for analyzing any changes during the storage of any formulation. For 3 months, all the formulations were kept in triplicate at $40^{\circ} \mathrm{C} \pm 2^{\circ} \mathrm{C}$ and $75^{\circ} \mathrm{C} \pm 5 \% \mathrm{RH}$ in stability chambers. By analyzing their folding endurance, drug content, and in vitro drug release, stability studies were evaluated [84].

\section{PACKAGING OF BUCCAL FILM}

At most care and precautions should be carried out while selecting packaging material to protect the integrity of the film. During the manufacturing and storage of these dosage forms, special care, processing, and high-quality packaging are essentially required. The ideal characteristics for selecting packaging materials are:

1. It should not get affected by the external environment.

2. It should be non-toxic.

3. It should be approved by the FDA.

4. It should not interact with the product.

5. It should meet the requirement of tamper-resistant [85].

Packaging for oral films generally includes foil, paper or plastic pouches, single pouch, aluminum pouch, blister cards with multiple units, and barrier films. Labtec GmbH formulated Rapid film technology which is a primary packaging made up of a sealing pouch having ample space for instructions, logos, codes, and other information. The laminating procedure was followed with an expense equal to that of tablets [86].

\section{Foil, paper, or plastic pouches}

It is a kind of flexible pouch which provides tamper-resistance along with a proper selection of material, overall a package of a high degree of environmental protection. It is formed during the procedure of product filling by vertical or horizontal forming, filling, and sealing equipment. They are available as single pouches or aluminum pouches [85].

\section{Single pouch and aluminum pouch}

For a quick-dissolving soluble film, a peel able soluble film drug delivery pouch is used with high barrier properties. It is a transparent pouch for the visibility of the product. It has a two-dimensional structure out of which one side is clear and the other one has a low-cost lamination of foil. The foil lamination is restricted to the transmission of gas and moisture [85]. A single-dose pouch protects the dose as well as the product whereas an aluminum pouch is most commonly used [87].

\section{Blister card with multiple units}

The blister container is made up of two components: 1. Blister 2. Lid stock

Blister has a cavity made up of plastic material to protect it from moisture which holds the product and lid stock is a material made up of aluminum foil which seals to the blister. It is formed by softening a sheet of thermoplastic resin by providing heat and contour molding the softened plastic sheet under vacuum. The sheet is removed from 
the mold after cooling and placed in the filling station of the packaging machine. The product is filled in the semi-rigid formed blister and sealed with a heat-sealable backing material as a lid stock [85].

\section{Barrier films}

Barrier films are generally required for those products which are highly sensitive to moisture. Certain materials which may protect from moisture are Poly chloro trifluoro ethylene (PCTFE) films, propylene. Propylene is a material that doesn't crack under stress. It provides an excellent barrier to vapors and gas. The only drawback related to barrier films is the lack of clarity [85].

\section{APPLICATIONS OF BUCCAL FILM}

\section{Vaccines}

An alternative to buccal films can be in the form of a vaccine for its fast dissolving action in mouth and saliva which are stable at room temperature. One such example is the rotavirus vaccine manufactured in the United States which has certain advantages such as enhanced bioavailability, improved patient compliance with minimal cost related to storage, handling, and administration [88].

\section{Controlled and sustained release}

In hospital preparations and various excipients of polymers such as chitosan derivatives, sustained-release buccal films are applicable as it contributes to wound dressings, decreasing toxicity, and good water resisting and adhesive properties [88].

\section{Nicotine replacement therapy (NRT)}

Nicotine in tobacco is a psychoactive substance leading to the habitual nature of smoking. In this therapy, the mucosal route of delivery is the most efficient as it readily permeates into the mucosal membrane. Pongjanyakul et al. formulated sodium alginate-magnesium aluminum silicate (SA-MAS) buccal film with the incorporation of nicotine. The study showed that SA-MAS films provided with a higher content of nicotine and slower permeation across the membrane compared to only SA films. Initially, drug release was faster and after $10 \mathrm{~h}$ controlled drug release was observed [89].

\section{Antifungal infections}

Fluconazole, a systemic antifungal for therapy of oral candidiasis, is generally preferred for mucosal delivery. Its systemic side effects can be reduced by increasing its oral concentration. Through mucoadhesive buccal films of small doses of fluconazole, there was an increase in the contact time between the drug and pathogenic yeast for a longer duration which eventually increased its efficacy [90].

\section{Management of herpes}

For the management of oral herpetic lesions, an antiviral drug acyclovir is most widely used. The permeability of acyclovir is low in oral mucosa which results in reduced efficacy. Hence, a study by Nair et al. formulated nanoparticles by incorporating polymeric materials and was loaded into films. The results provided good mucoadhesive strength and great physicomechanical property with improved oral bioavailability of acyclovir [91].

\section{Targeted therapy for oral cancer}

The most approved treatment for oral cancer is the targeted therapy which aims for site-specific delivery with low levels of toxicity and side effects. By acquiring nano delivery systems in the form of films consisting of polymers, it has been concluded an increase in solubility, stability, and bioavailability accumulated even inside tumor cells. A study was conducted for the development of liposomes loaded in the film and was evaluated for its cytotoxicity in hematopoietic stem cells (HSC-3) [92].

\section{Cardiovascular diseases}

One of the major cardiovascular diseases that need to be under control with long-term therapy is hypertension. Antihypertensives such as carvedilol, propranolol, and metoprolol have a short half-life and low oral bioavailability due to poor aqueous solubility and high first-pass metabolism. To overcome this, the buccal mucoadhesive system was established as it provides a direct pathway into the systemic circulation through the internal jugular vein by preventing the first-pass effect of obtaining high bioavailability [93]. A lower effective dose of $3.125 \mathrm{mg}$ of carvedilol produces higher efficacy with increasing contact time and bypassing the first-pass metabolism [94].

\section{Hypoglycemic agents}

Recently for hypoglycemic agents such as glipizide and glibenclamide buccal delivery system has been introduced. Administration of 2 or 3 doses of 2.5-10 mg daily of glipizide leads to short biological half-life. Uptake of water by the film was seen when the water-insoluble drug was incorporated [95]. Different grades of HPMC with measured ratios were used for preparing glibenclamide mucoadhesive buccal films. In conclusion, buccal drug delivery can be useful in a controlled pattern at a low concentration of HPMC3000 [96]. Hypoglycemic activity has also been found in the fruit of Cucumis callosus belonging to family Cucurbitaceae [97].

\section{Antiemetic}

Ondansetron HCL shows certain properties such as low molecular weight and biphasic solubility that is an ideal characteristic for absorption through the buccal mucosa. Its bioavailability may get improved by the mucosal route as its primary route for clearance was through hepatic Phase I metabolism. Patients suffering from vomiting during chemotherapy find it difficult to swallow a tablet. Hence, it is justified that buccal film increases patient compliance by preventing the need for swallowing [98]. Nausea and vomiting associated with cancer chemotherapy is distinct from typical nausea and vomiting that many people experience in their normal daily life though the drugs used may be the same [99]

\section{Asthma}

The buccal patches have been formulated for delivery of sodium cromoglycate for treatment of asthma. The drug has short half-life and it was need to formulate it in a controlled release system. The results of inclusion of this drug in buccal patches led to extension of the time required to attain maximum concentration in the blood in addition to showing a reduction in the maximum plasma concentration in the blood. It also provided controlled release of the drug [100].

\section{CONCLUSION}

The present review concludes that the buccal film is that the most accurate and acceptable dosage form, due to higher patient compliance, faster drug delivery system, and bypasses the hepatic first-pass effect and shows enhance bioavailability. Buccal films will replace the conventional dosage forms, as well as fast disintegrating tablets due to its advantages over the conventional dosage forms, and they can be manufactured at a low cost. A range of dosage forms can be incorporate in buccal drug delivery. However, buccal films are more feasible formulation because of its simplicity in preparation, drug loading, and characterization. Buccal films will be a more robust choice to optimize the therapeutic efficacy of various API in the future. The oral mucoadhesive dosage forms can continue to be an exciting research focus on improving drug absorption, particularly for the new generation.

\section{ACKNOWLEDGMENTS}

The authors are thankful to the Faculties of H.K College Of Pharmacy for guiding the preparation of this manuscript.

\section{AUTHORS CONTRIBUTION}

Literature search and preparation have been done by Reesha Baig, Gaurang Sawant and Shifa Haju. Manuscript Framing and the concept has been presented by Shifa Haju. Reviewed and editing have been done by Dr. Sheela Yadav. 


\section{CONFLICT OF INTERESTS}

The authors have declared no conflicts of interest.

\section{AUTHORS FUNDING}

As this is a review article, no funding was provided for this study.

\section{REFERENCES}

1. Madhavi RB, Murthy VS, Rani PA, Gattu DK. Buccal film drug delivery system an innovative and emerging technology. J Mol Pharm Org Process Res 2013;1:100-7.

2. Patel NA, Shah DP, Patel TJ. A novel approach for buccal drug delivery system-buccal film. Pharm Sci Monit 2016;7:166-83.

3. Semalty A, Semalty M, Nautiyal U. Formulation and evaluation of mucoadhesive buccal films of enalapril maleate. Indian J Pharm Sci 2010;72:571-5.

4. Bhati R, Nagarajan R. A detailed review on oral mucosal drug delivery system. Int J Pharm Sci 2012;3:659-81.

5. Shojaei AH. Buccal mucosa as a route for systemic drug delivery: A review. J Pharm Pharm Sci 1998;1:15-30.

6. Verma S, Kaul M, Rawat A, Sanil A. An overview on buccal drug delivery system. Int J Pharm Sci 2011;2:1303-21.

7. Lee JW, Park JH, Robinson JR. Bioadhesive-based dosage forms: The next generation. J Pharm Sci 2000;89:850-66.

8. Veuillez F, Kalia YN, Jacques J, Deshusses, Buri P. Factor and strategies for improving buccal absorption of peptides. Eur J Pharm Biopharm 2001;51:93-109.

9. Gawas S M, Dev A, Deshmukh G, Rathod S. Current approaches in buccal drug delivery system. Pharm Biol Eval 2016;3:165-77.

10. Shrivastava G. A novel approach for buccal drug delivery system. World J Pharm Pharm Sci 2015;4:1744-60.

11. Joseph RR, Vincet KL. Lee Controlled Drug Delivery. $2^{\text {nd }}$ ed. New York: Marcel Decker Inc.; 1987. p. 42-3.

12. Rao NGR, Shravani B, Reddy MS. Overview on buccal drug delivery systems. J Pharm Sci Res 2013;5:80-8.

13. Banarjee T. A review on fast dissolving films for buccal delivery. Int $\mathbf{J}$ Sci Res 2015;1:117-23.

14. Nayaka SK, Manjunath K, Pawan C. Formulation and evaluation of mucoadhesive buccal films of dothiepin HCL. Int J Pharm Pharm Res 2020;18:535-48

15. Mamatha Y, Prasanth VV, Selvi A, Sipai AM, Yadav V. Buccal drug delivery a technical approach. J Drug Deliv Ther 2012;2:26-33

16. Bhowmik D, Niladry C. Mucoadhesive buccal drug delivery system an overview. J Adv Pharm Educ Res 2013;3:319-31.

17. Miller NS, Johnston TP. The use of mucoadhesive polymers in buccal drug delivery. Adv Drug Deliv 2002;57:1666-91.

18. Ramesh B. A review on buccal drug delivery system. Int J Res Pharm Sci 2014;5:200-20.

19. Moataz MF, Mohamed JS. Creation and assessment of buccal mucoadhesive sustained release oral films. Int J Pharm Pharm Res 2019;16:30-41.

20. Khairnar GA, Sayyad FJ. Development of buccal drug delivery system based on mucoadhesive polymer. Int J Pharm Tech Res 2010;2:719-35.

21. Benedict A, Mathew MM, Sathyan J, Thomas J. Buccal film: An emerging technology for oral drug delivery. Int J Pharm Pharm Res 2017:9:204-13.

22. Puratchikody A, Prasanth VV, Mathew ST, Kumar AB. Buccal drug delivery: Past, present and future a review. Int J Drug Deliv 2011;3:171-84.

23. Alexander A, Ajazuddin S, Tripathi DK, Verma T, Maurya J, Patel S. Mechanism responsible for mucoadhesion of drug delivery system: A review. Int J App Biol Pharm Technol 2011;2:434-45.

24. Roychowdhury S, Gupta R, Saha S. A review on buccal mucoadhesive drug delivery systems. Indo Glob J Pharm Sci 2011;1:223-33.

25. Singh R, Sharma D, Garg R. Review on mucoadhesive drug delivery system with special emphasis on buccal route: An important tool in designing of novel controlled drug delivery system for the effective delivery of pharmaceuticals. J Dev Drugs 2017;6:1-2.

26. Malpure DR, Deore SL. Buccal mucoadhesive films: A review. Syst Rev Pharm 2017;8:31-8.

27. Patel M, Karigar A, Savaliya P, Ramana NV, Ashwini M. Buccal drug delivery system: The current interest. Int J Pharm 2011;2:4-11.

28. Bhalodia R, Basu B, Garala K. Buccoadhesive drug delivery system. Int J Pharm Biol Sci 2010;2:1-31.

29. Ramesh B, Saravanakumar K, Nagaveni P, Kumar V. A review on buccal drug delivery system. Int J Res 2014;5:200-4.
30. Reddy PC, Chaitanya KS, Rao YM. A review on bioadhesive buccal drug delivery systems: Current status of formulation and evaluation methods. Daru 2011;19:385-403.

31. Muhammad UM, Safwan S. Buccal patches: An advanced route of drug dosage delivey a review. Int J Pharm Pharm Res 2017;10:206-16.

32. Kumar V, Aggarwal G, Zakir F, Choudhary A. Buccal bioadhesive drug delivery a novel technique. Int J Pharm Bio Sci 2011;1:89-102.

33. Shaikh R, Singh TR, Donnelly RF. Mucoadhesive drug delivery systems. J Pharm Bioallied Sci 2011;3:89-100.

34. Rajaram DM, Sharada DL. Buccal mucoadhesive films: A review. Syst Rev Pharm 2017;8:31-8.

35. Sheoran R. Buccal drug delivery system: A review. Int J Pharm Sci Rev Res 2018;50:40-6.

36. Jagtap VD. Buccal film a review on novel drug delivery system. Int J Res Rev 2020;7:17-28.

37. Samita G, Kumar G. Fast dissolving drug delivery and its technologies. Pharm Innov 2012;1:34-39.

38. Bhandari HP, Yadav J. Review on mucoadhesive buccal drug delivery. Pharm Sci Monit 2018;9:345-362.

39. Madhav NV, Semwal R, Semwal DK, Semwal RB. Recent trends in oral transmucosal drug delivery systems: An emphasis on the soft palatal route. Expert Opin Drug Deliv 2012;9:629-47.

40. Dahiya M, Saha S, Shahiwala AF. A review on mouth dissolving films. Curr Drug Deliv 2009;6:469-76.

41. Daněk Z, Gajdziok J, Doležel P, Landová H, Vetchý D, Štembírek J. Buccal films as a dressing for the treatment of aphthous lesions. J Oral Path Med 2017;46:301-6.

42. Sakellariou P, Rowe RC. Interactions in cellulose derivative films for oral drug delivery. Prog Polym Sci 1995;20:889-942.

43. McIndoe LM, Rowe RC, Sheskey PJ, Owen SC. Handbook of Pharmaceutical Excipients. London: Pharmaceutical Press; 2006. p. 128-30.

44. Rekha MS, Sultana SK, Mahathi K, Parveen P, Prathima B, Devi AS. Formulation and evaluation of fast dissolving buccal film containing isradipine solid dispersion. Am J Pharm Tech Res 2015;5:221-47.

45. Dave V, Mishra A. A review on promising novel drug delivery systembioadhesive drug delivery system. Curr Res Pharm Sci 2017;7:69-78.

46. Prakash I, Dubois GE, Clos JF, Wilkens KL, Fosdick LE. Development of rebiana, a natural, non-caloric sweetener. Food Chem Toxicol 2008;46:S75-82.

47. Balakrishna T. Formulation and evaluation of lansoprazole fast dissolving buccal films. Asian J Pharm 2018;12:2422.

48. Wale A, Weller PJ. Handbook of Pharmaceutical Excipients. $2^{\text {nd }}$ ed. Washington, DC: American Pharmaceutical Association; 1994. p. 24, $27,352,448$

49. Barnhart SD, Sloboda MS. Dissolvable films the future of dissolvable films. Drug Dev Tech 2007;1:34-5.

50. Mahajan A, Chhabra N, Aggarwal G. Formulation and characterization of fast dissolving buccal films: A review. Pharm Lett 2011;3:152-65.

51. Pol SV, Jagtap RS, Doijad RC, Desai JR, Pawar JD, Jadhav VV, et al. Review on fast dissolving buccal film: An emergency treatment. Int $\mathrm{J}$ Innov Sci Res Tech 2017;2:277-81.

52. Vishwakarma AK. A review on oral films: From theory to practice. Rex J 2017;4:432-43.

53. Patel A. In vitro and in vivo evaluation of chitosan/Karaya Gum Interpolymer complex based mucoadhesive buccal films of tramadol HCL. Asian J Pharm 2018;11:1721.

54. Kulkarni AS, Deokule HA, Mane MS, Ghadge DM. Exploration of different polymers for use in the formulation of oral fast dissolving strips. J Curr Pharm Res 2010;2:33-5.

55. Ansari M, Sadarani B, Majumdar A. Optimization and evaluation of mucoadhesive buccal films loaded with resveratrol. J Drug Deliv Sci Tech 2018;44:278-88

56. Irfan M, Rabel S, Bukhtar Q, Qadir MI, Jabeen F, Khan A. Orally disintegrating films: A modern expansion in drug delivery system. Saudi Pharm J 2016;24:537-46.

57. Juluru NS. Fast dissolving oral films: A review. Int J Adv Pharm Biol Chem 2013;2:108-12.

58. Xu J, Bovet LL, Zhao K. Taste masking microspheres for orally disintegrating tablets. Int J Pharm 2008;359:63-9.

59. Morales JO, McConville JT. Manufacture and characterization of mucoadhesive buccal films. Eur J Pharm Biopharm 2011;77:187-99.

60. Perumal VA, Lutchman D, Mackraj I, Govender T. Formulation of monolayered films with drug and polymers of opposing solubilities. Int J Pharm 2008;358:184-91.

61. Kohda Y, Kobayashi H, Baba Y, Yuasa H, Ozeki T, Kanaya Y, et al. Controlled release of lidocaine hydrochloride from buccal mucosa- 
adhesive films with solid dispersion. Int J Pharm 1997;158:147-55.

62. Wong C, Yuen K, Peh K. Formulation and evaluation of controlled release Eudragit buccal patches. Int J Pharm 1999;178:11-22.

63. Khanna R, Agarwal SP, Ahuja A. Preparation and evaluation of bio erodible buccal tablets containing clotrimazole. Int J Pharm 1996;138:67-73

64. Amin PM, Gangurde AB, Alai PV. Oral film technology: Challenges and future scope for pharmaceutical industry. Int J Pharm Pharm Res 2015;3:184-203.

65. Ceballos A, Cirri M, Maestrelli F, Corti G, Mura P, influence of formulation and process variables on in-vitro release of theophylline from directly compressed Eudragit matrix tablets IL. Farmaco 2005;60:913-8.

66. Lala R, Thorat AA, Gargote CS, Awari NG. Preparation of buccoadhesive polymeric film of ketoprofen and its evaluation. Asian J Pharm Sci 2011;6:267-74.

67. Basahih TS, Alamoudi AA, El-Say KM, Alhakamy NA, Ahmed OA. Improved transmucosal delivery of glimepiride via unidirectional release buccal film loaded with Vitamin E TPGS-based nanocarrier. Dose Response 2020;18:1-12.

68. Jagdale S, Hable A, Chabukswar A, Kuchekar B. Improvement of dissolution rate of chlorzoxazone by solid dispersion technique and development of buccal patch. J Appl Solution Chem 2013;2:145-57.

69. Gherman S, Zavastin D, Ochiuz L, Biliuta G, Coseri S. Enalapril maleate loaded pullulan film for mucoadhesive buccal drug delivery applications. Cell Chem Technol 2016;50:593-600.

70. Sarojini S. Formulation development of olmesartan medoxomil mucoadhesive buccal film. Asian J Pharm 2016;10:S510-7.

71. Kianfar F, Chowdhry BZ, Antonijevic MD, Boateng JS. Novel films for drug delivery via the buccal mucosa using model soluble and insoluble drugs. Drug Dev Ind Pharm 2012;38:1207-20.

72. Lohani A, Prasad N, Rajeshwar KK. Formulation and characterization of mucoadhesive buccal films of ranitidine hydrochloride. Int J Pharm Sci Res 2011;2:2457-62.

73. Abouhussein DM, Abd El-Bary A, Shalaby SH, El-Namarari MA. Chitosan mucoadhesive buccal films: Effect of different casting solvents on their physicochemical properties. Int J Pharm Pharm Sci 2016;8:206-13.

74. Deepthi A, Reddy BV, Navaneetha K. Formulation and evaluation of fast dissolving oral films of zolmitriptan. Am J Adv Drug Deliv 2014;2:153-63.

75. Govindasamy P, Reddy BK, Narasimha JK. Formulation of unidirectional release buccal patches of carbamazepine and study of permeation through porcine buccal mucosa. Asian Pac J Trop Biomed 2013;3:995-1002.

76. Peddapalli H, Chinnala KM, Nagaraj B. Design and in vitro characterization of mucoadhesive buccal patches of duloxetine hydrochloride. Int J Pharm Pharm Sci 2017;9:52-9.

77. Kaur A, Kaur G. Mucoadhesive buccal patches based on interpolymer complexes of chitosan-pectin for delivery of carvedilol. Saudi Pharm J 2012;20:21-7

78. Gorle A, Patli P, Bhaskar R, Ola M. Development and evaluation of buccal film containing antihypertensive agent. J Pharm Innov 2015;4:53-60.

79. Kshirasagar N, Thamada N, Naik VN, Gopla MS. Design and evaluation of chitosan containing mucoadhesive buccal patch fluoxetine HCL. Int J Sci Res 2012;2:1-5.
80. Salehi S, Boddohi S. New formulation and approach for mucoadhesive buccal film of rizatriptan benzoate. Prog Biomater 2017;6:175-87.

81. Doijad RC, Manvi FV, Rao VS, Patel PS. Buccoadhesive drug delivery system of isosorbide dinitrate: Formulation and evaluation. Int J Pharm Sci 2006;68:744-8

82. Ammanage A, Rodriques P, Kempwade A, Hiremath R. Formulation and evaluation of buccal films of piroxicam co-crystals. Future J Pharm Sci 2020;6:16.

83. Lodhi M, Dubey A, Narayan R, Prabhu P, Priya S. Formulation and evaluation of buccal film of Ivabradine hydrochloride for the treatment of stable angina pectoris. Int J Pharm Investig 2013;3:47.

84. Bulhe PJ, Mahajan SK, Ghule P. Formulation and evaluation of buccal patches by using natural gum. Int J Res Pharm Chem 2016;6:684-95.

85. Lachmann L. The Theory and Practical of Industrial Pharmacy. $3^{\text {rd }}$ ed. India: Varghese Publishing House; 1991. p. 344-8.

86. Muhammad I, Rabel S, Bukhtar Q, Muhammad IQ, Jabeen F, et al. Orally disintegrating films: A modern expansion in drug delivery system. Saudi Pharm J 2016;24:537-46.

87. Kaur M, Rana AC, Seth N. Fast dissolving films: An innovative drug delivery system. Int J Pharm Res All Sci 2001;2:14-24.

88. Habib W, Khankari R, Hontz J. Fast-dissolve drug delivery system. Crit Rev Ther Drug Carr Sys 2000;17:61-72.

89. Pongjanyakul T, Suksri H. Alginate-magnesium aluminum silicate films for buccal delivery of nicotine. Colloids Surf B Biointerfaces 2009;74:103-13.

90. Yehia SA, El-Gazayerly ON, Basalious EB. Design and in vitro/in vivo evaluation of novel mucoadhesive buccal discs of an antifungal drug: Relationship between swelling, erosion, and drug release. AAPS PharmSciTech 2008;9:1207-17.

91. Nair AB, Al-Ghannam AA, Al-Dhubiab BE, Hasan AA. Mucoadhesive film embedded with acyclovir loaded biopolymeric nanoparticles: In vitro studies. J Young Pharm 2017;9:100-5.

92. Jin $\mathrm{BZ}$, Dong $\mathrm{XQ}, \mathrm{Xu} \mathrm{X}$, Zhang $\mathrm{FH}$. Development and in vitro evaluation of mucoadhesive patches of methotrexate for targeted delivery in oral cancer. Oncol Lett 2018;15:2541-9.

93. Gilhotra RM, Ikram M, Srivastava S, Gilhotra N. A clinical perspective on mucoadhesive buccal drug delivery systems. J Biomed Res 2014;28:81-97.

94. Thimmasetty J, Pandey GS, Babu S Pr. Design and in vivo evaluation of carvedilol buccal mucoadhesive patches. Pak J Pharm Sci 2008;21:241-8.

95. Semalty M, Semalty A, Kumar G. Formulation and characterization of mucoadhesive buccal films of glipizide. Indian J Pharm Sci 2008;70:43-8.

96. Muzib YI, Kumari KS. Mucoadhesive buccal films of glibenclamide: Development and evaluation. Int J Pharma Investig 2011;1:42-7.

97. Panda SP, Haldar PK, Das SU. In vitro hypoglycemic and antimicrobial activity of Cucumis callosus (Rottl.) Cogn fruit. Asian J Pharm Clin Res 2016;9:77-81

98. Hassan N, Khar RK, Ali M, Ali J. Development and evaluation of buccal bioadhesive tablet of an anti-emetic agent ondansetron. AAPS PharmSciTech 2009;10:1085-92.

99. James EM, Drisya PM, Jose WM. Olanzapine combined with standard antiemetic regimens for prevention of chemotherapy therapy-induced nausea and vomiting: A single-center experience from South India. Asian J Pharm Clin Res 2017:10:247-51.

100. Sabry SA. Sodium cromoglycate mucoadhesive buccal patches: Design, fabrication, in vitro and in vivo characterization. Int J Appl Pharm 2018;10:76-82. 